Supporting Information

\title{
Single-step Flame Aerosol Synthesis of Active and Stable Nanocatalysts for the Dry Reforming of Methane
}

\author{
Mohammad Moein Mohammadi, Chintan Shah, Sandeep Kumar \\ Dhandapani, Junjie Chen, Shema Rachel Abraham, William Sullivan, \\ Raymond D. Buchner, Eleni A. Kyriakidou, Haiqing Lin, Carl R. F. Lund, \\ Mark T. Swihart \\ Department of Chemical and Biological Engineering, University at Buffalo, The State University \\ of New York, Buffalo, NY 14260, USA \\ swihart@buffalo.edu
}


Synthesis of NiMgO-FI and NiMgO-Cl: First, the MgO supports (MgO from the HTRJ process and commercial $\mathrm{MgO}$ (Aldrich, nanopowder, $\leq 50 \mathrm{~nm}$ particle size (BET)) were precalcined at $550{ }^{\circ} \mathrm{C}$ in air to remove moisture and impurities. Then, an aqueous solution of $\mathrm{MgO}$ was mixed with desired amount of nickel nitrate aqueous solution $(0.1 \mathrm{M})(\mathrm{Mg} / \mathrm{Ni}$ wt. ratio of 9). The mixture was kept under vigorous stirring for $2 \mathrm{~h}$, followed by drying at $60{ }^{\circ} \mathrm{C}$ for $24 \mathrm{~h}$. The sample was then calcined by heating to $450{ }^{\circ} \mathrm{C}$ at a ramping rate of $1^{\circ} \mathrm{C} \mathrm{min}-1$ in $\mathrm{Ar}$ and holding at $450^{\circ} \mathrm{C}$ for $2 \mathrm{~h}$.

Synthesis of NiMgO-CP: An aqueous solution of magnesium nitrate (1 M) was mixed with the desired amount of nickel nitrate aqueous solution (1 M) ( $\mathrm{Mg} / \mathrm{Ni}$ wt. ratio of 9$)$. The mixed solution then was added dropwise to a $\mathrm{Na}_{2} \mathrm{CO}_{3}$ solution $(1 \mathrm{M})$ under vigorous stirring. The $\mathrm{pH}$ was adjusted to 10 by adding $\mathrm{NaOH}$ solution (10 M). The obtained mixture was kept at $75^{\circ} \mathrm{C}$ for $1 \mathrm{~h}$ under stirring. Subsequently, the resulting gel was filtered and washed, then dried at $60{ }^{\circ} \mathrm{C}$ in a vacuum oven overnight, followed by calcination by heating to $650^{\circ} \mathrm{C}$ at a ramping rate of $1^{\circ} \mathrm{C} \mathrm{min}-1$ in $\mathrm{Ar}$ and holding at $650{ }^{\circ} \mathrm{C}$ for $2 \mathrm{~h}$.

\section{Nickel dispersion and surface area calculations:}

The nickel dispersion was calculated from $\mathrm{CO}$ pulse chemisorption using the Equation s1.

$$
D=\left(\frac{V_{S} \times S F}{S W \times M \times 22414}\right) G M W \times 100 \quad \text { Equation S1 }
$$

$D=$ active metal percent dispersion

$V_{S}=$ Volume (carbon monoxide) sorbed $(\mathrm{CO}, \mathrm{cm} 3$ at STP)

$S F=$ Stoichiometry factor, in this work, Ni/CO $=1$ was applied.

SW = Sample weight $(g)$

GMW = Gram Molecular Weight of Ni (g/gmole) 
$M=$ Ni loading

The Ni surface area per gram of sample was calculated based on the Equation S2.

$$
S A_{\text {metallic }}=\left(\frac{V_{S} \times S F_{\text {calc }}}{S \mathrm{~W} \times \mathrm{M} \times 22414}\right) \times\left(6.123 \times 10^{23}\right) \times S A \quad \text { Equation S2 }
$$

$S A_{\text {metallic }}=$ metallic surface area $\left(\mathrm{m}^{2} / \mathrm{g}\right.$ of sample $)$

$V_{S}=$ Volume (carbon monoxide) sorbed $\left(\mathrm{cm}^{3}\right.$ at STP)

$S F_{\text {calc }}=$ Stoichiometry factor, in this work, $\mathrm{NI} / \mathrm{CO}=1$ was applied.

$S A=$ Specific surface area of $\mathrm{Ni}$ atom

SW $=$ Sample weight $(g)$

$\mathrm{M}=\mathrm{Ni}$ loading

The Ni dispersion calculation and $\mathrm{Ni}$ surface area calculations are based on the CO pulse chemisorption results, which only titrates the accessible metallic $\mathrm{Ni}$ after a reductive pretreatment (same pretreatment as the DRM reaction). The reduction degree was not considered in this case. 


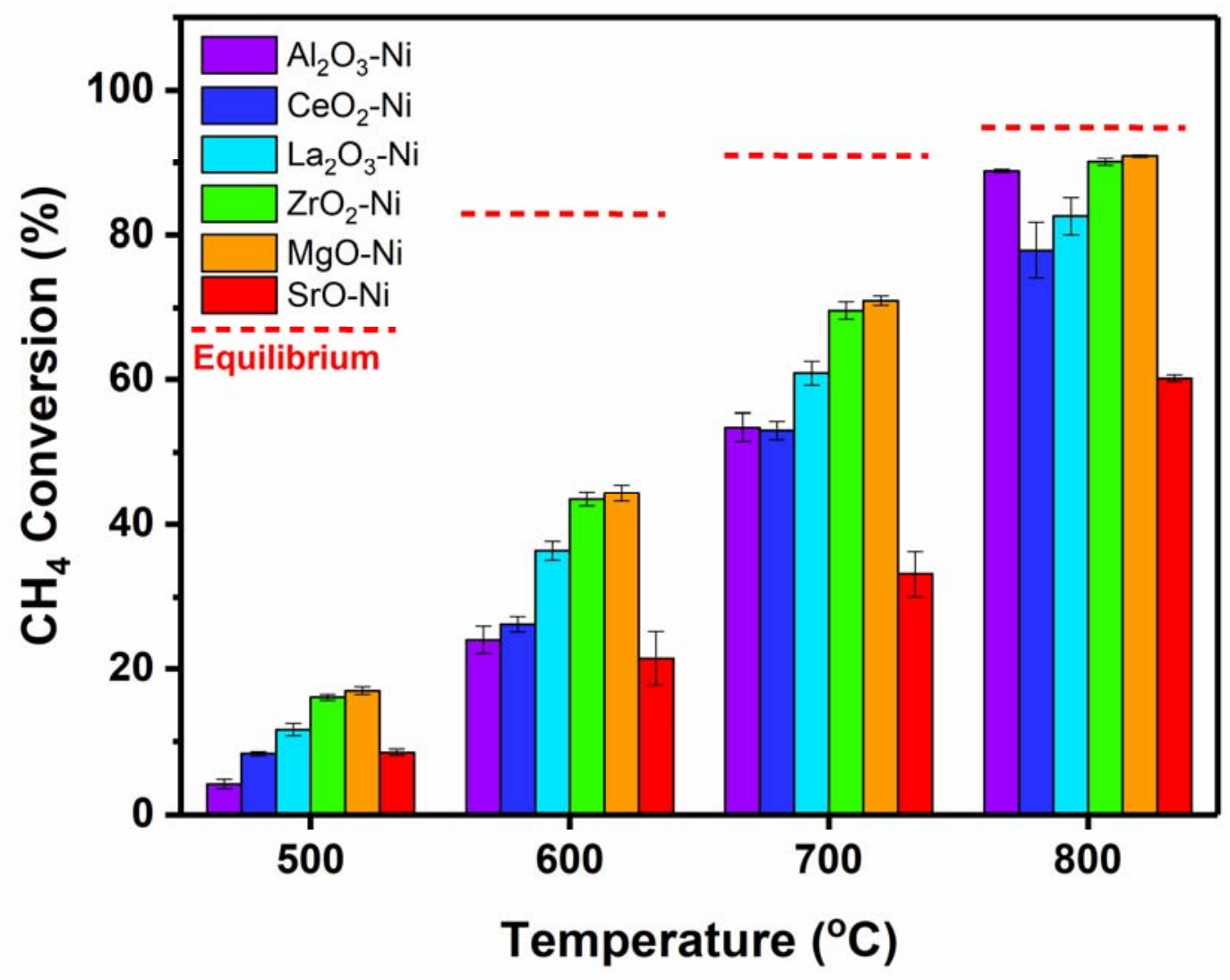

Figure S1. Methane conversion achieved using various nickel-based catalysts at different temperatures. All values are mean \pm standard deviation. Feed flow rate per total catalyst mass of $60,000 \mathrm{~mL} \mathrm{gcat}^{-1} \mathrm{~h}^{-1}$. (Supports with almost no activity: $\mathrm{Na}, \mathrm{Ca}, \mathrm{K}, \mathrm{V}$ ). All catalysts were produced directly by the HTRJ process. 


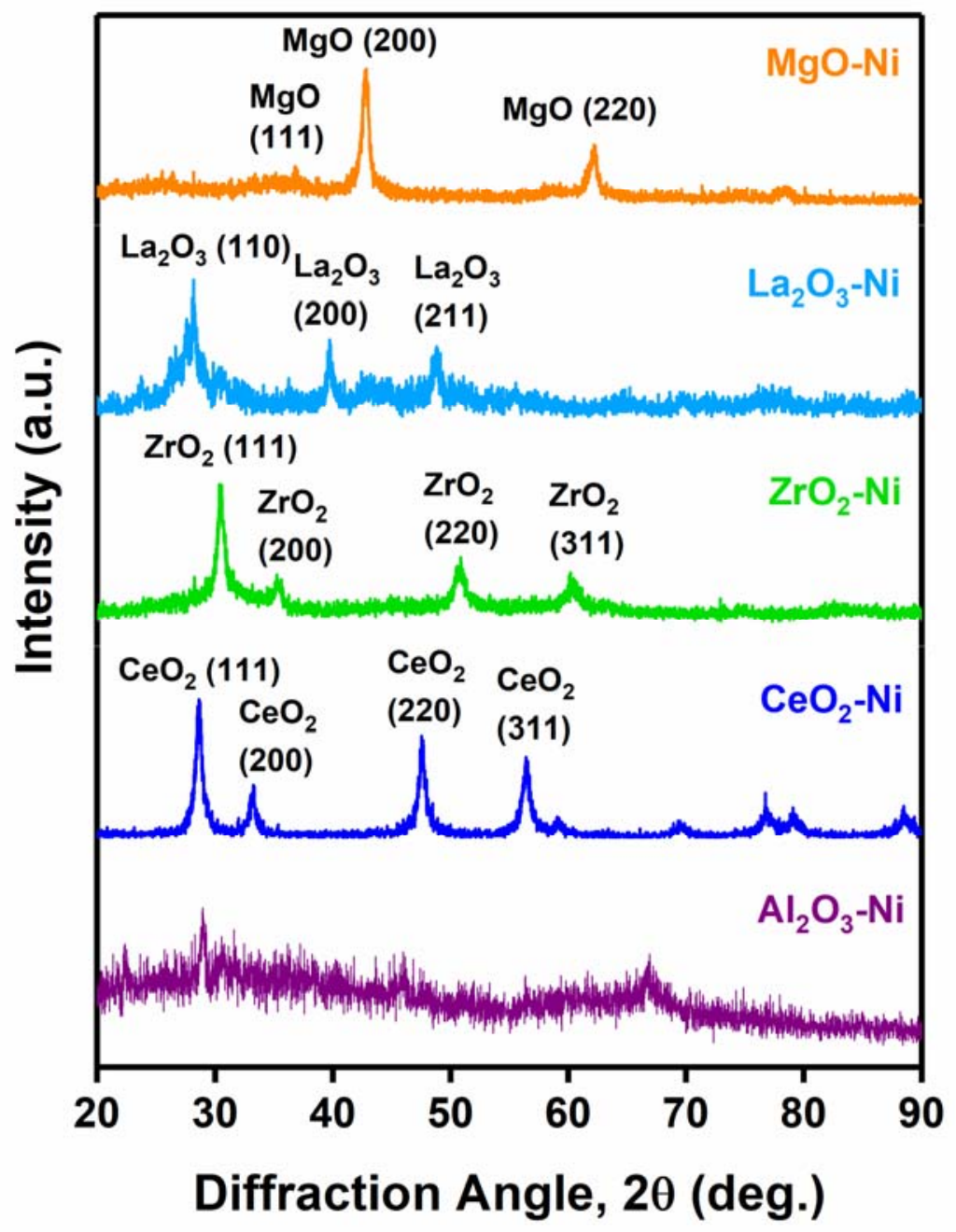

Figure S2. XRD patterns of the as-prepared nickel-based catalysts produced using the HTRJ process. 

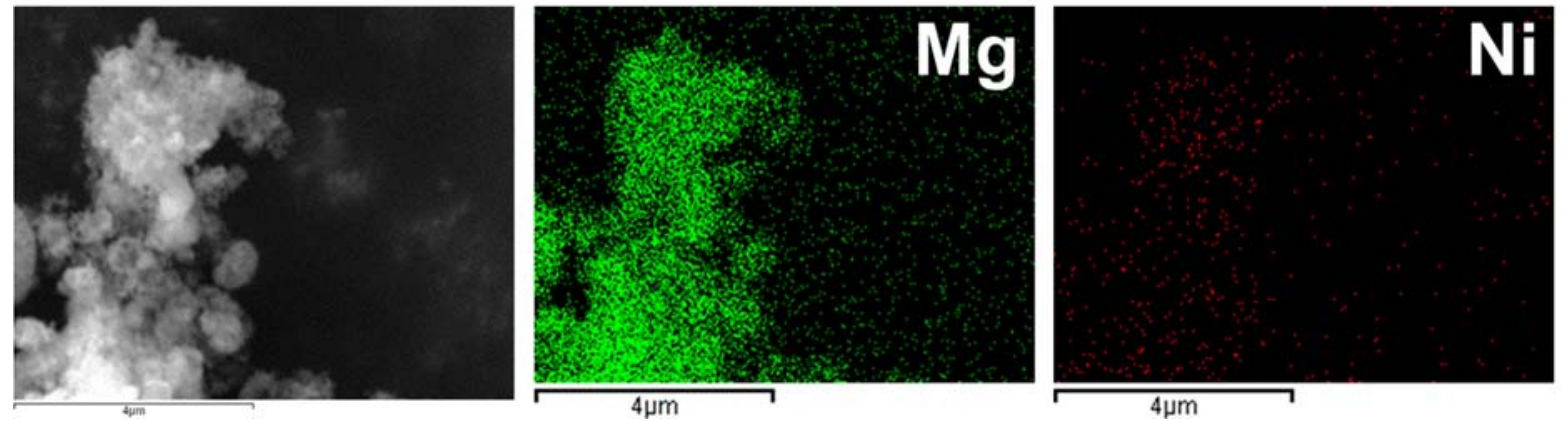

Figure S3. SEM image and the corresponding elemental maps for $\mathrm{Mg}$ and $\mathrm{Ni}$ for the reduced NiMgO-F catalyst. 

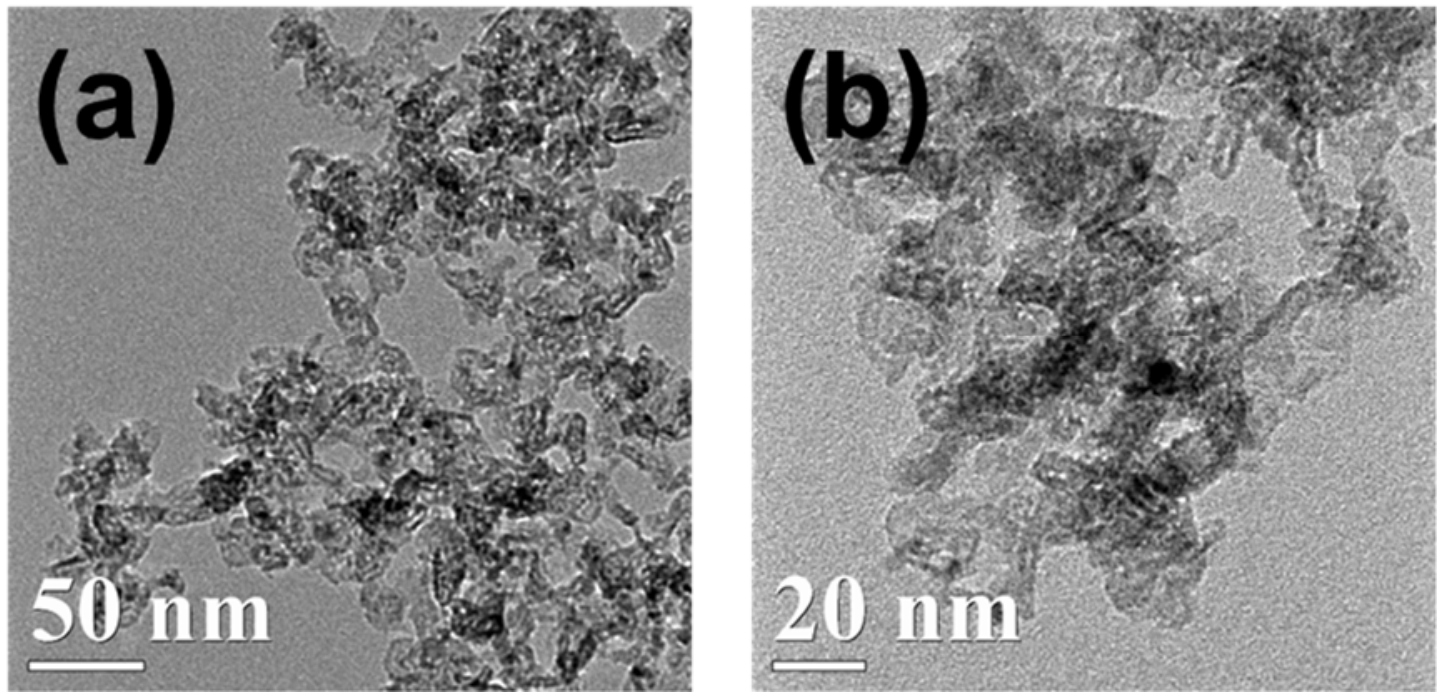

Figure S4.a,b) TEM images of the reduced NiMgO-F catalyst. 


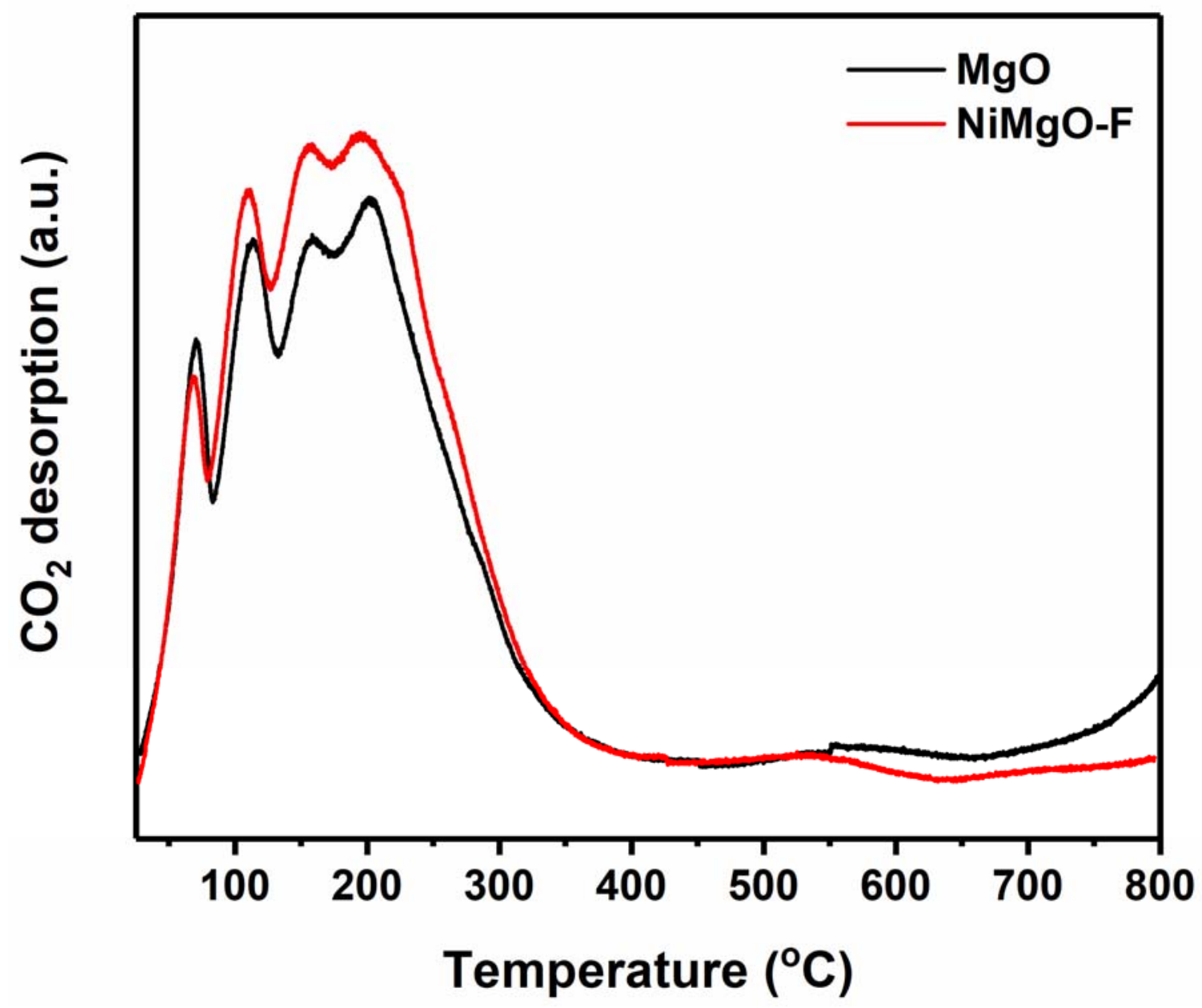

Figure S5. $\mathrm{CO}_{2}$-TPD analysis of $\mathrm{MgO}$ support and NiMgO-F catalyst. 


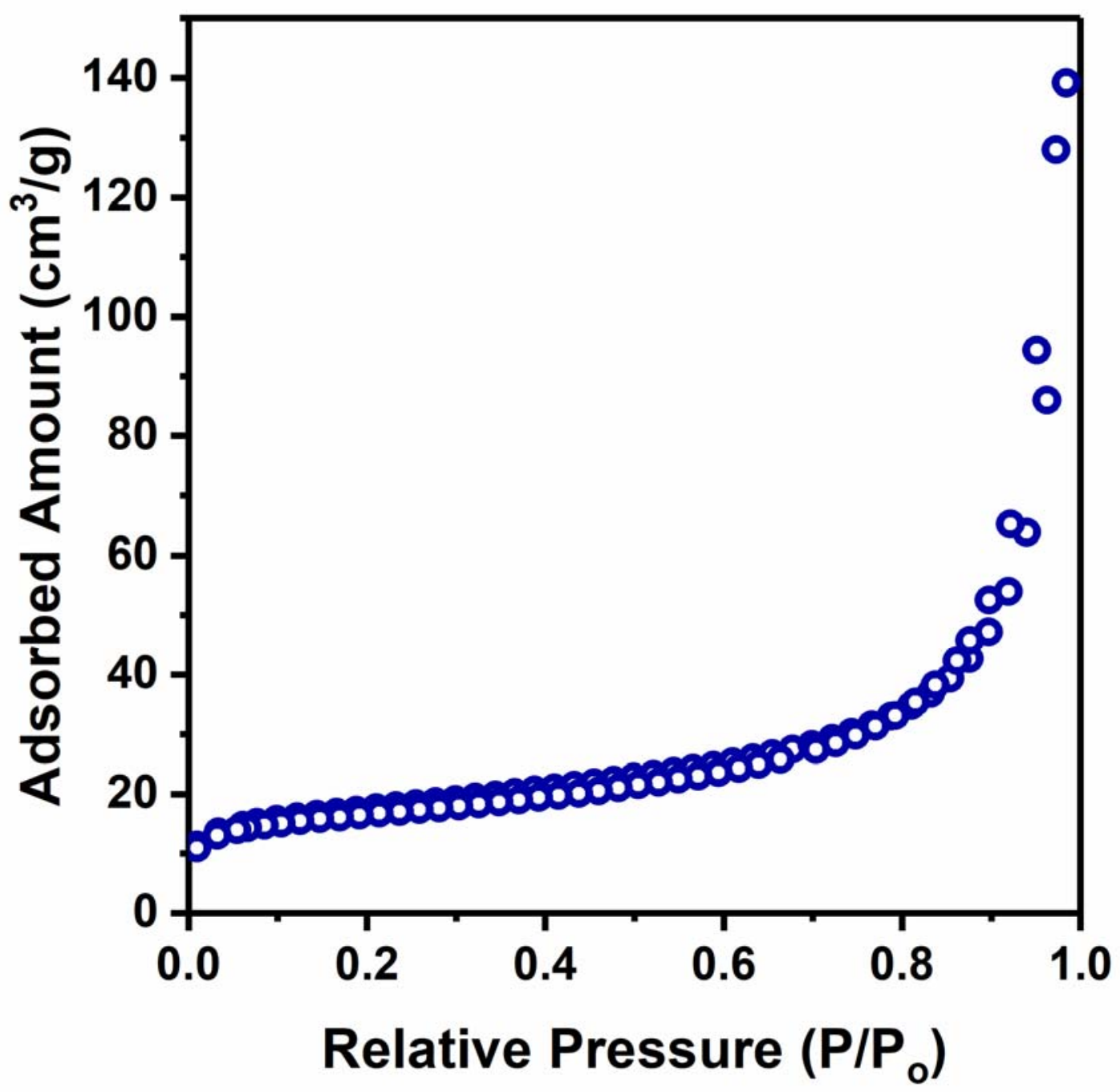

Figure S6. Nitrogen physisorption isotherm used for BET surface area analysis of NiMgO-F. 

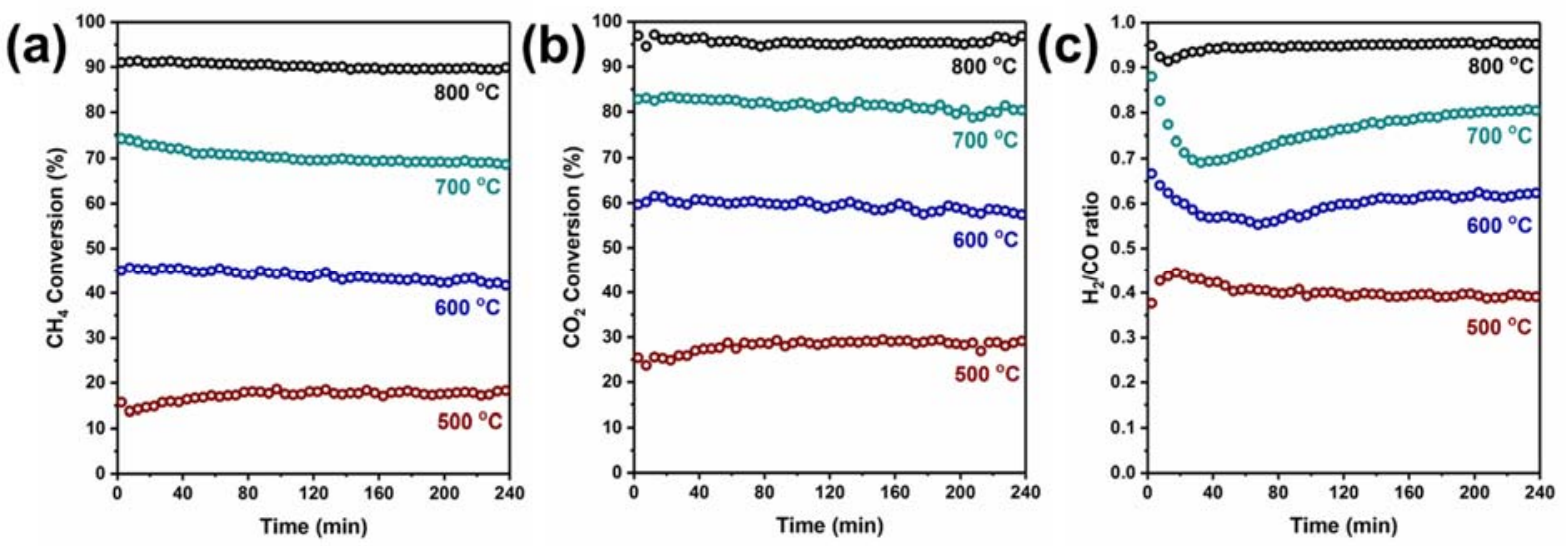

Figure S7. The activity of NiMgO-F catalyst at 4 temperatures: a) $\mathrm{CH}_{4}$ conversion; b) $\mathrm{CO}_{2}$ conversion; c) $\mathrm{H}_{2} / \mathrm{CO}$ ratio. (gas flow to catalyst mass ratio: $60000 \mathrm{~mL} /\left(\mathrm{g}_{\text {cat }} \mathrm{h}\right.$ ), no diluent gas). 


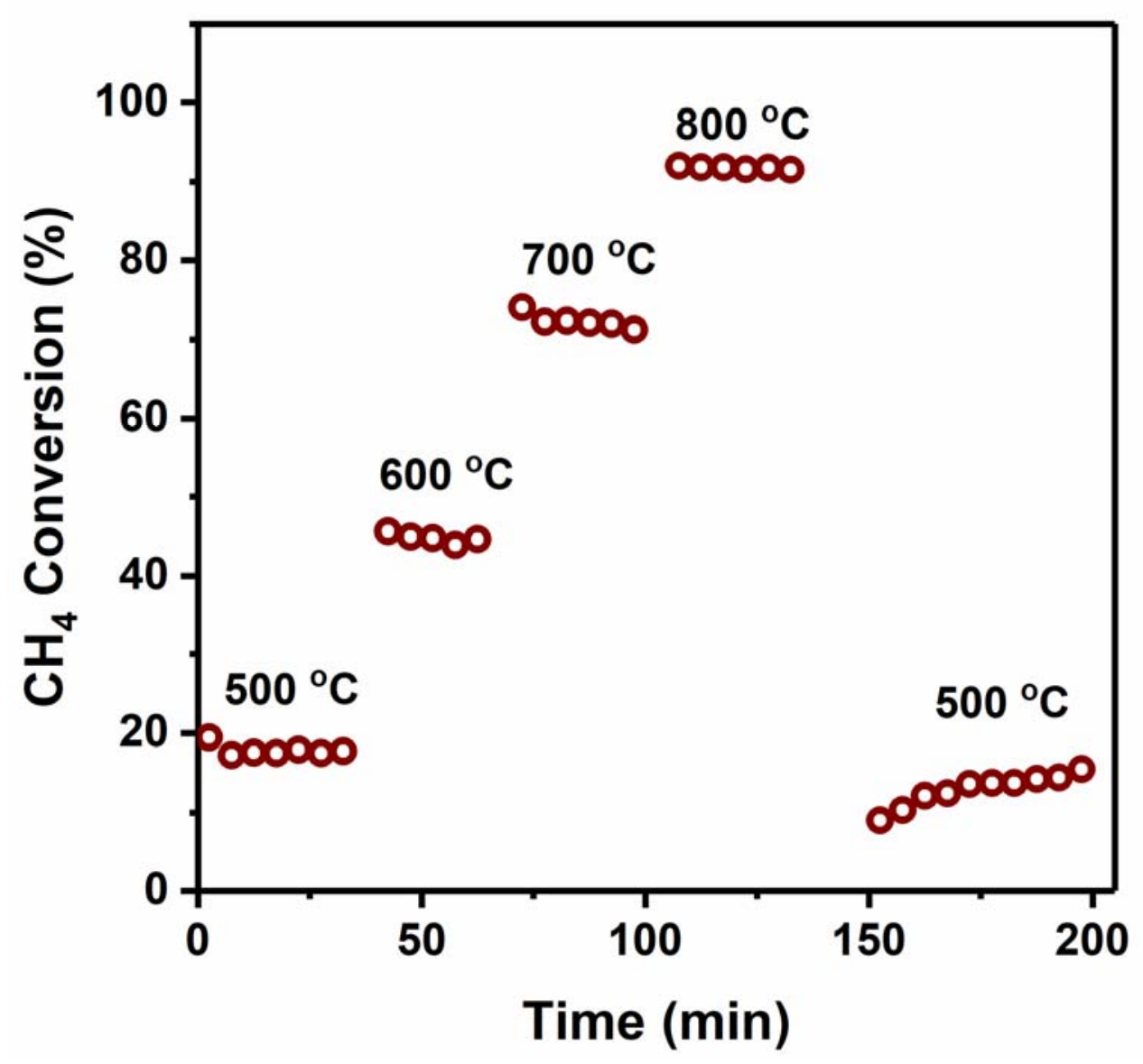

Figure S8. Recovery test for the NiMgO-F catalyst. 


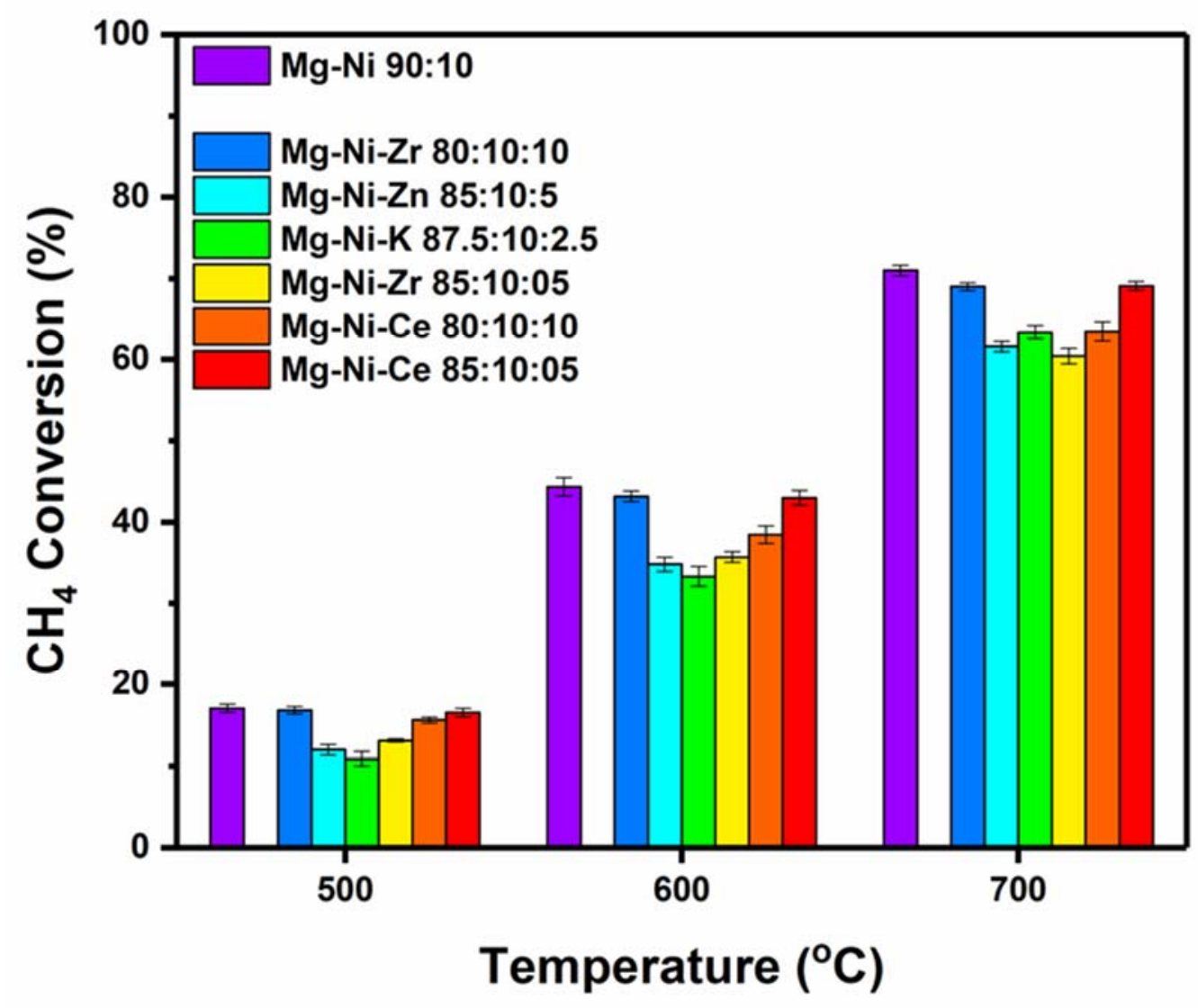

Figure S9. Methane conversions for different catalysts with potential promoters. Feed flow rate per total catalyst mass of $60,000 \mathrm{~mL} \mathrm{gcat}^{-1} \mathrm{~h}^{-1}$. All values are mean \pm standard deviation. 


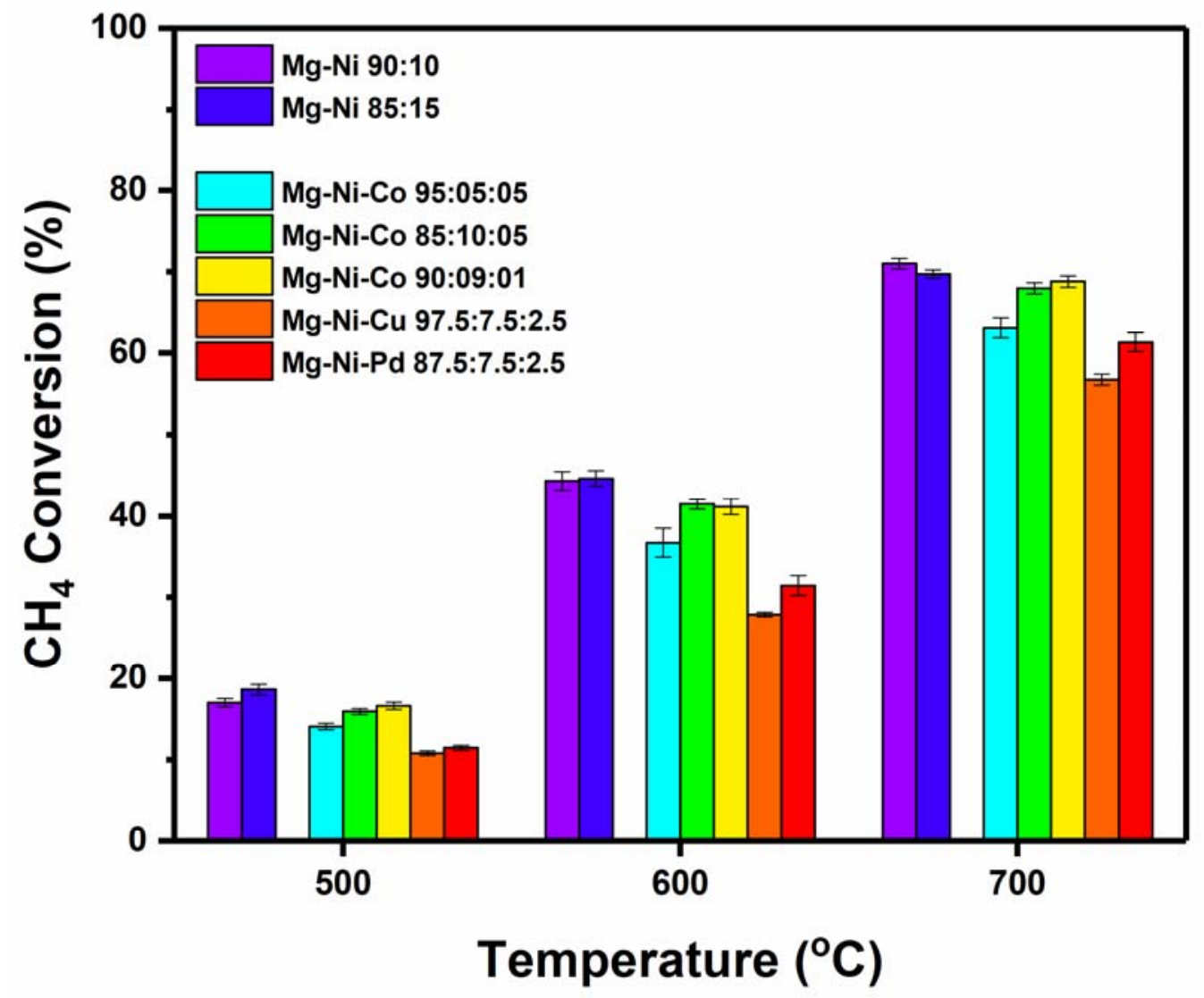

Figure S10. Methane conversions for different catalysts with co-catalysts. Feed flow rate per total catalyst mass of $60,000 \mathrm{~mL} \mathrm{gcat}^{-1} \mathrm{~h}^{-1}$. All values are mean \pm standard deviation. 


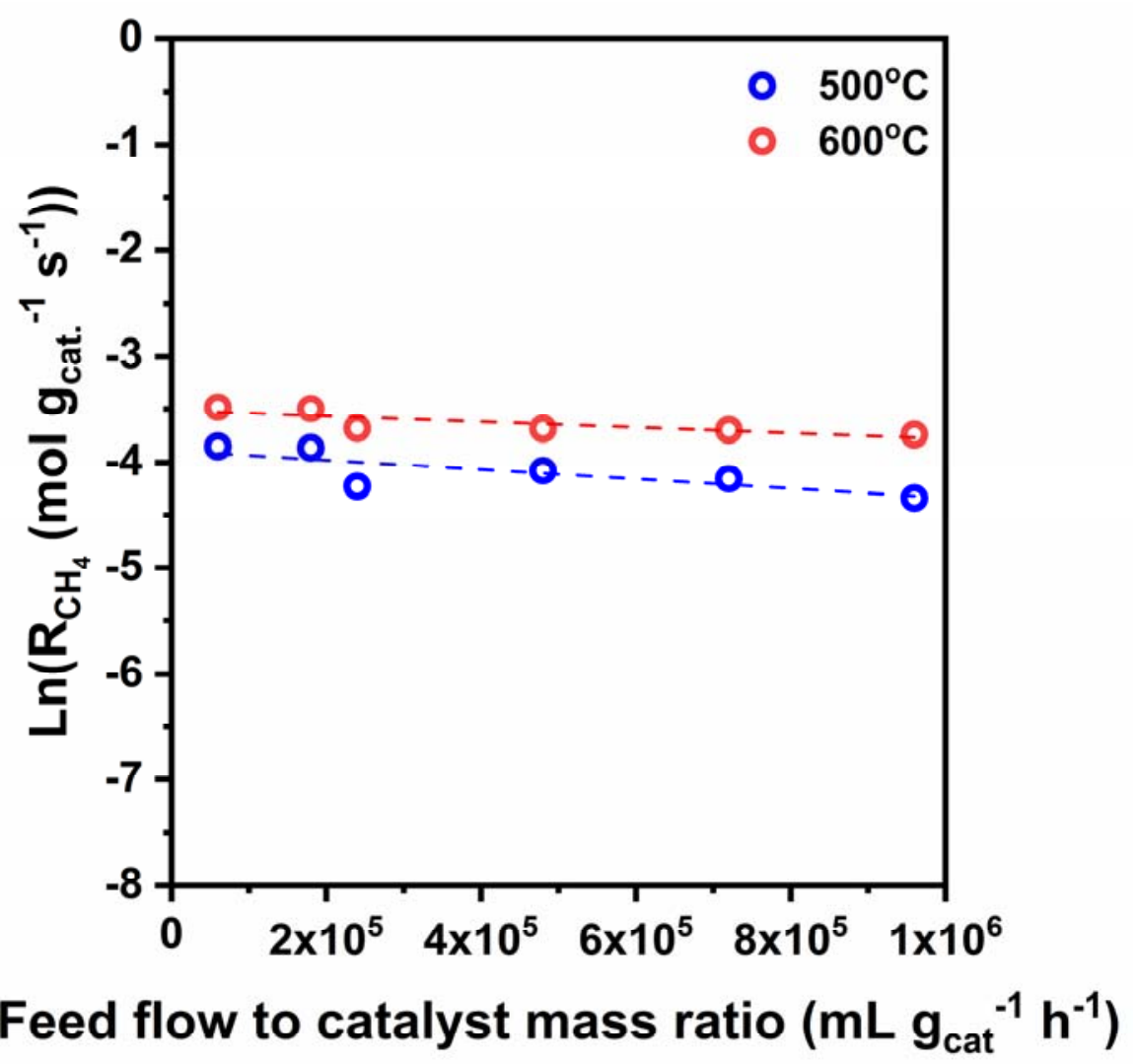

Figure S11. Calculated methane reaction rate at various feed flow to catalyst mass ratios at 500 and $600^{\circ} \mathrm{C}$. 

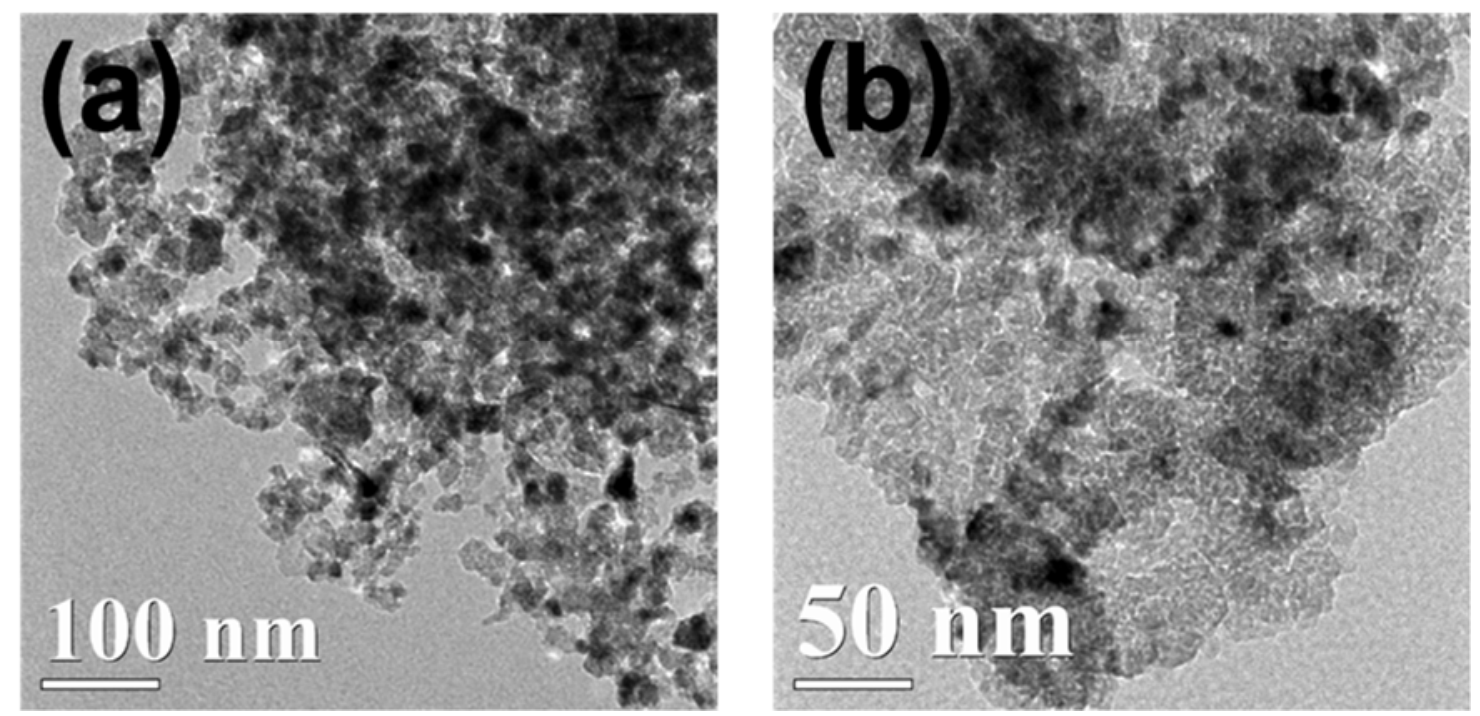

Figure S12.a,b) TEM images of NiMgO-FI catalyst. 

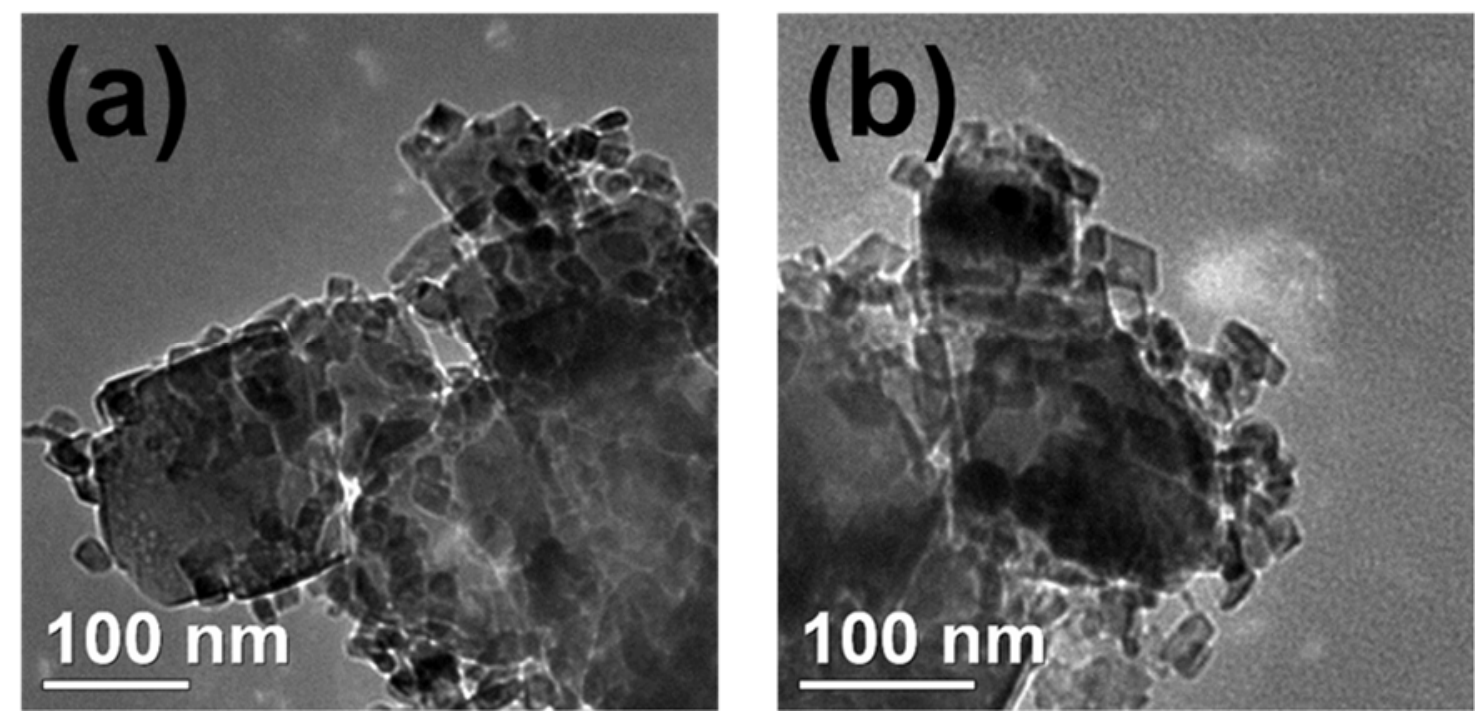

Figure S13.a,b) TEM images of NiMgO-Cl catalyst. 

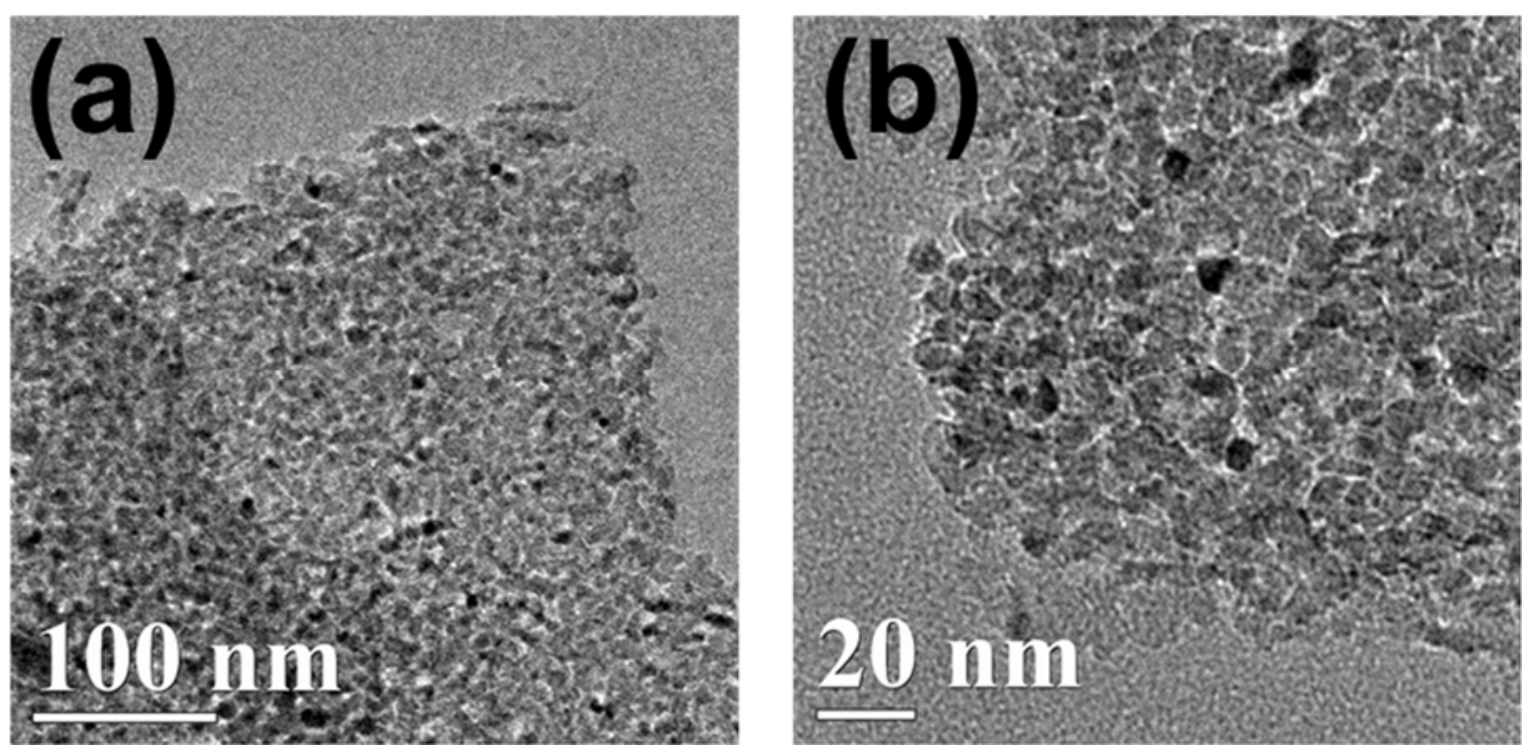

Figure S14.a,b) TEM images of NiMgO-CP catalyst. 

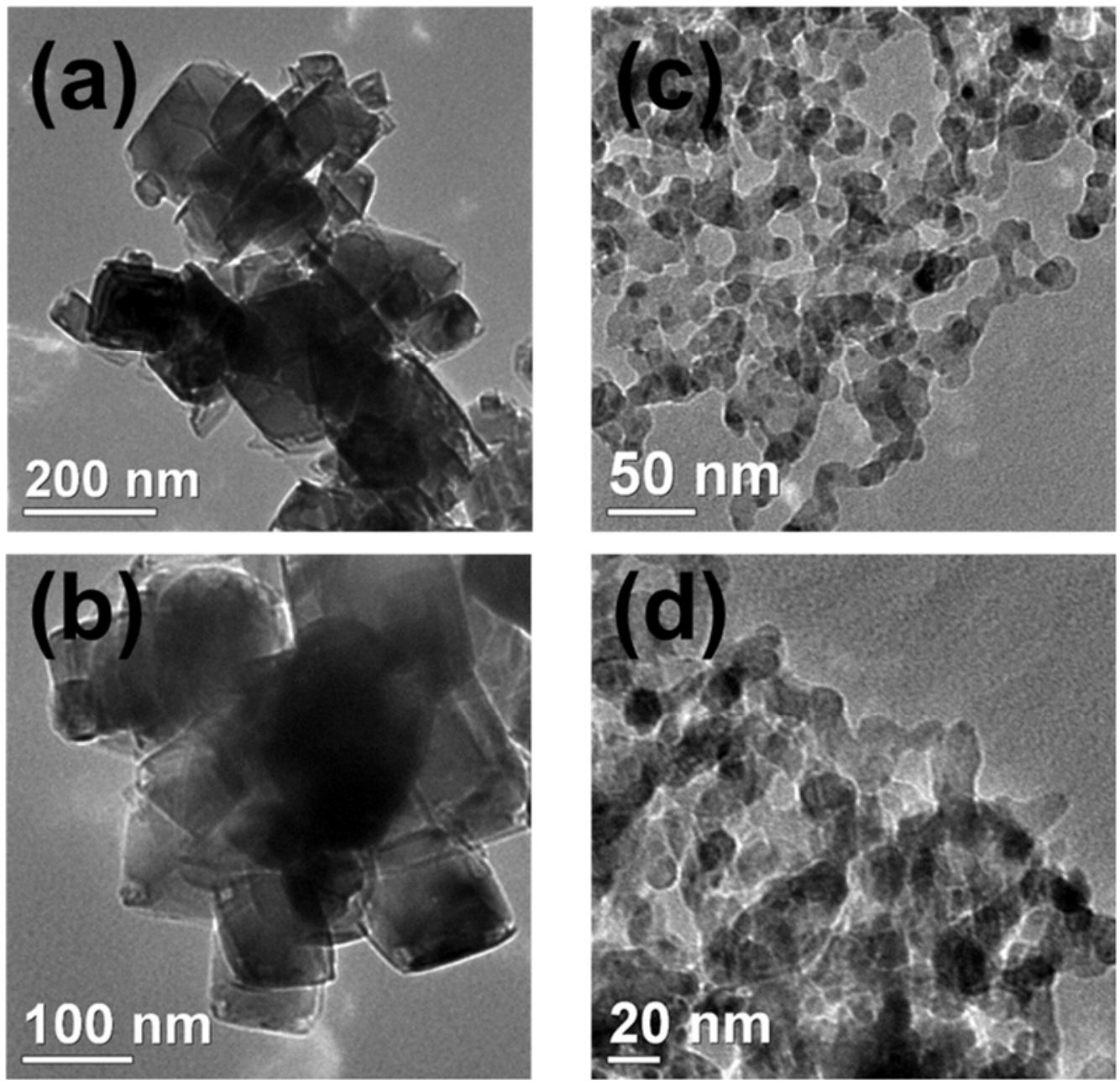

Figure S15. Comparison of TEM images of $\mathbf{a , b}$ ) commercial $\mathrm{MgO}$, and $\mathbf{c}, \mathbf{d}) \mathrm{MgO}$ produced by the HTRJ process. 


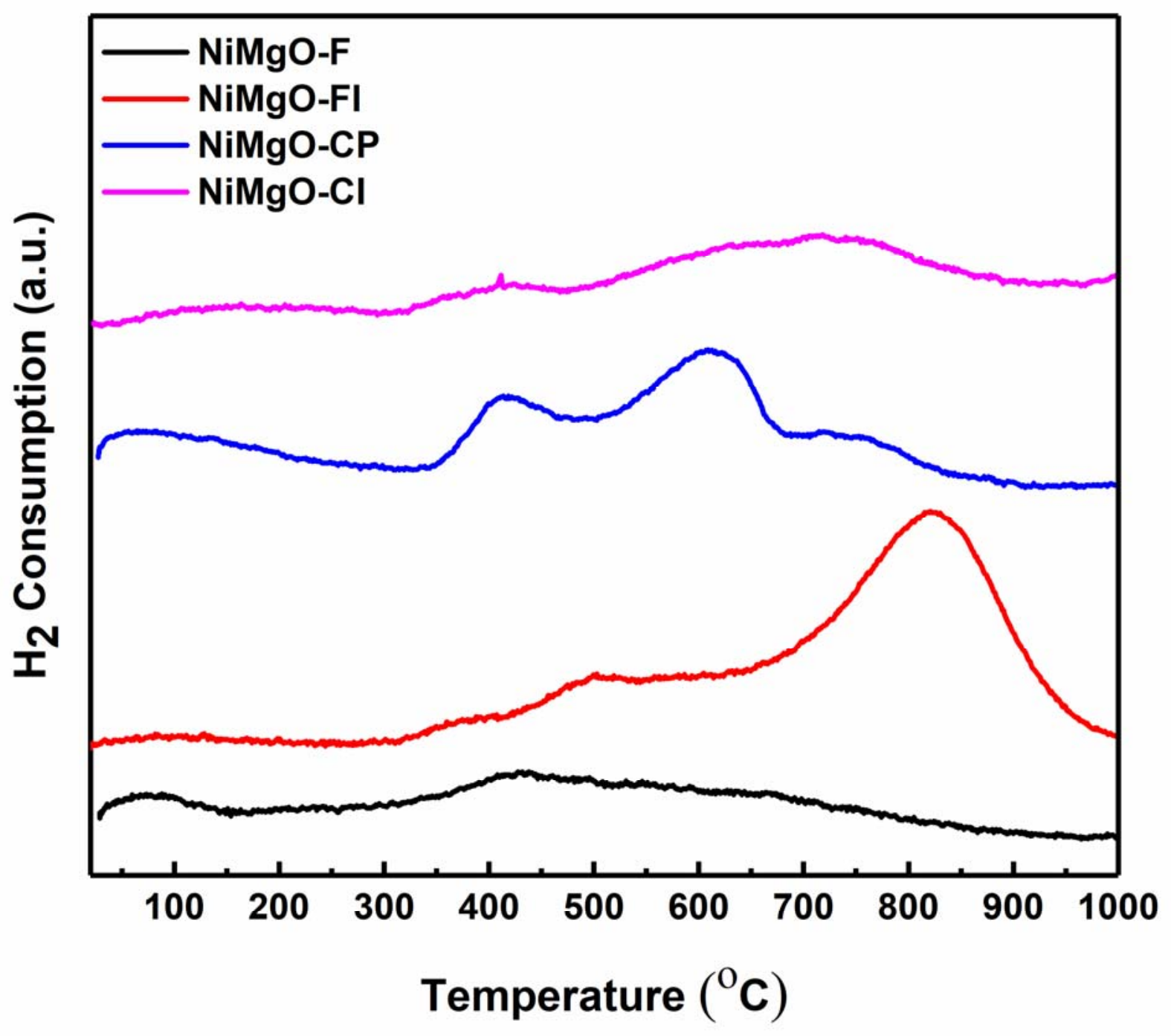

Figure $\mathrm{S} 16 . \mathrm{H}_{2}$-TPR analysis of the catalysts. 

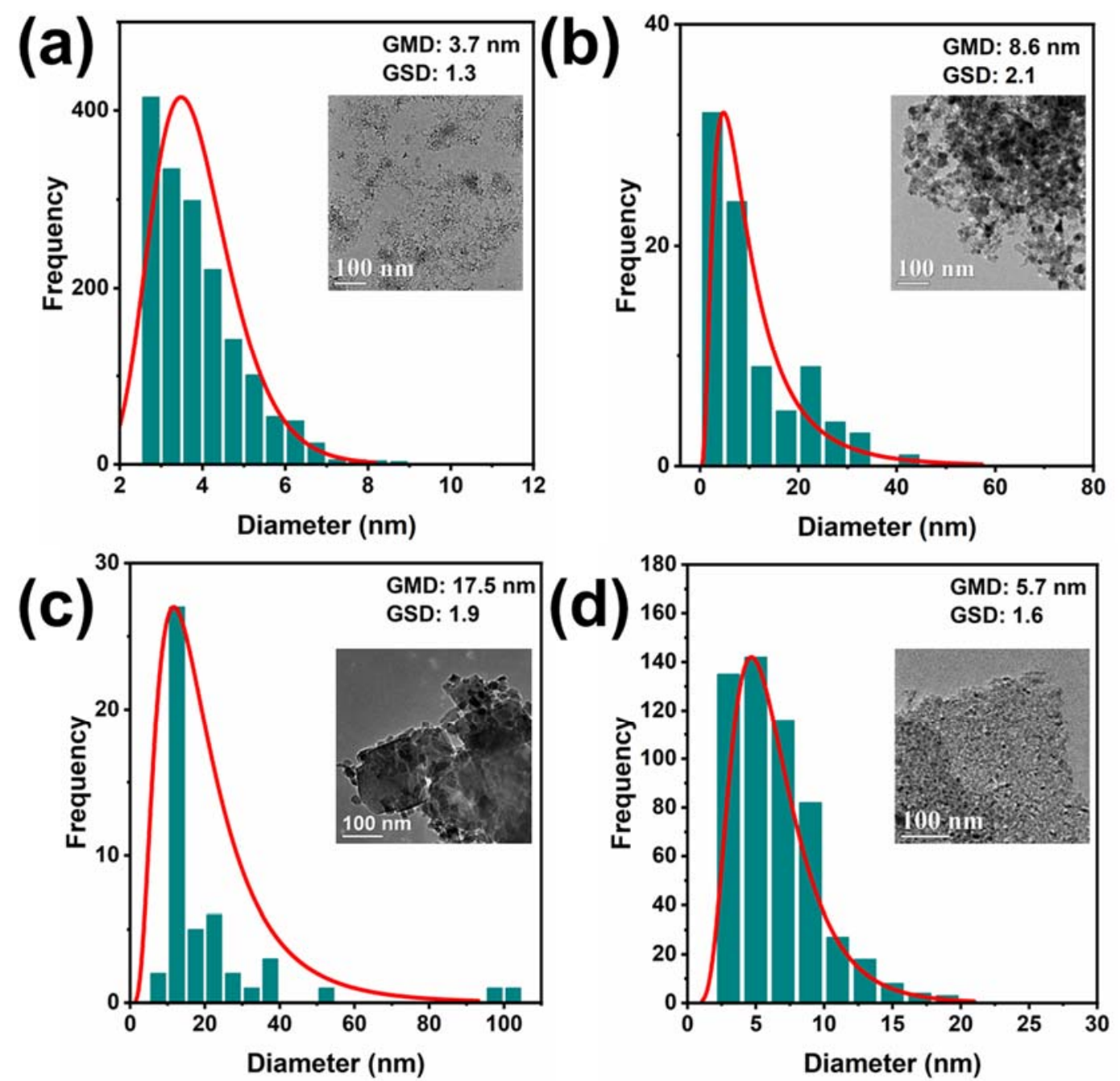

Figure S17. TEM images and the corresponding particle size distributions for: a) $\mathrm{NiMgO}-\mathrm{F}$; b) NiMgO-FI; c) NiMgO-Cl; d) NiMgO-CP. (GMD: Geometric Mean Diameter, GSD: Geometric Standard Deviation) 


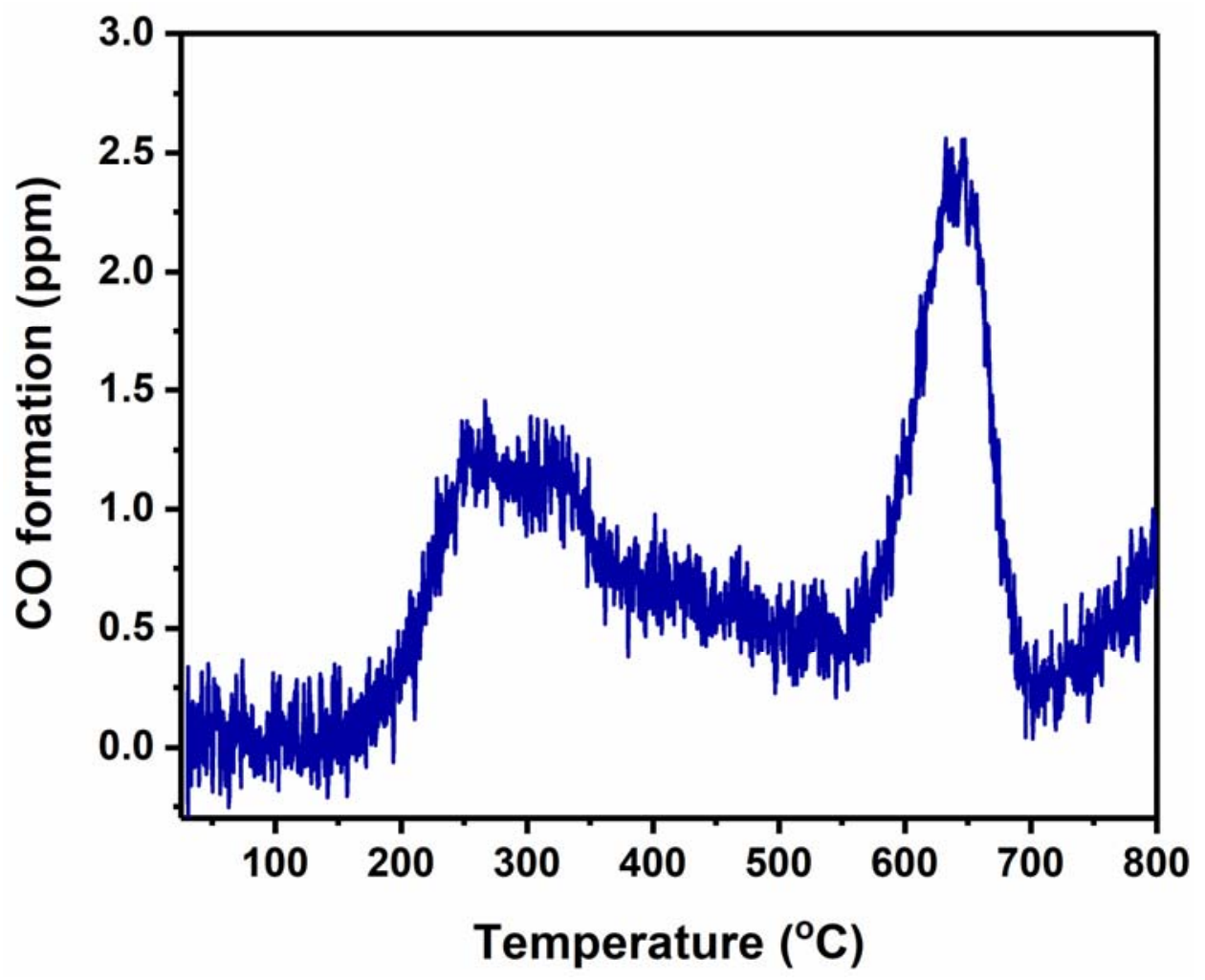

Figure S18. CO formation during the $\mathrm{O}_{2}$-TPO analysis 


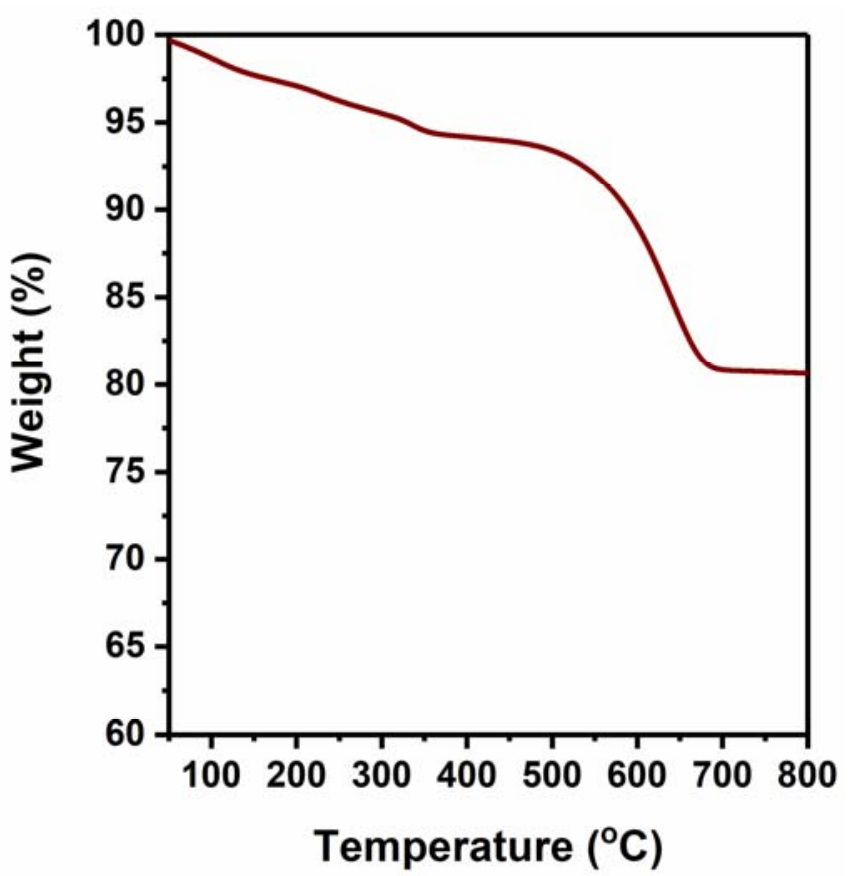

Figure S19. TGA analysis of the spent NiMgO-F after the stability test. 


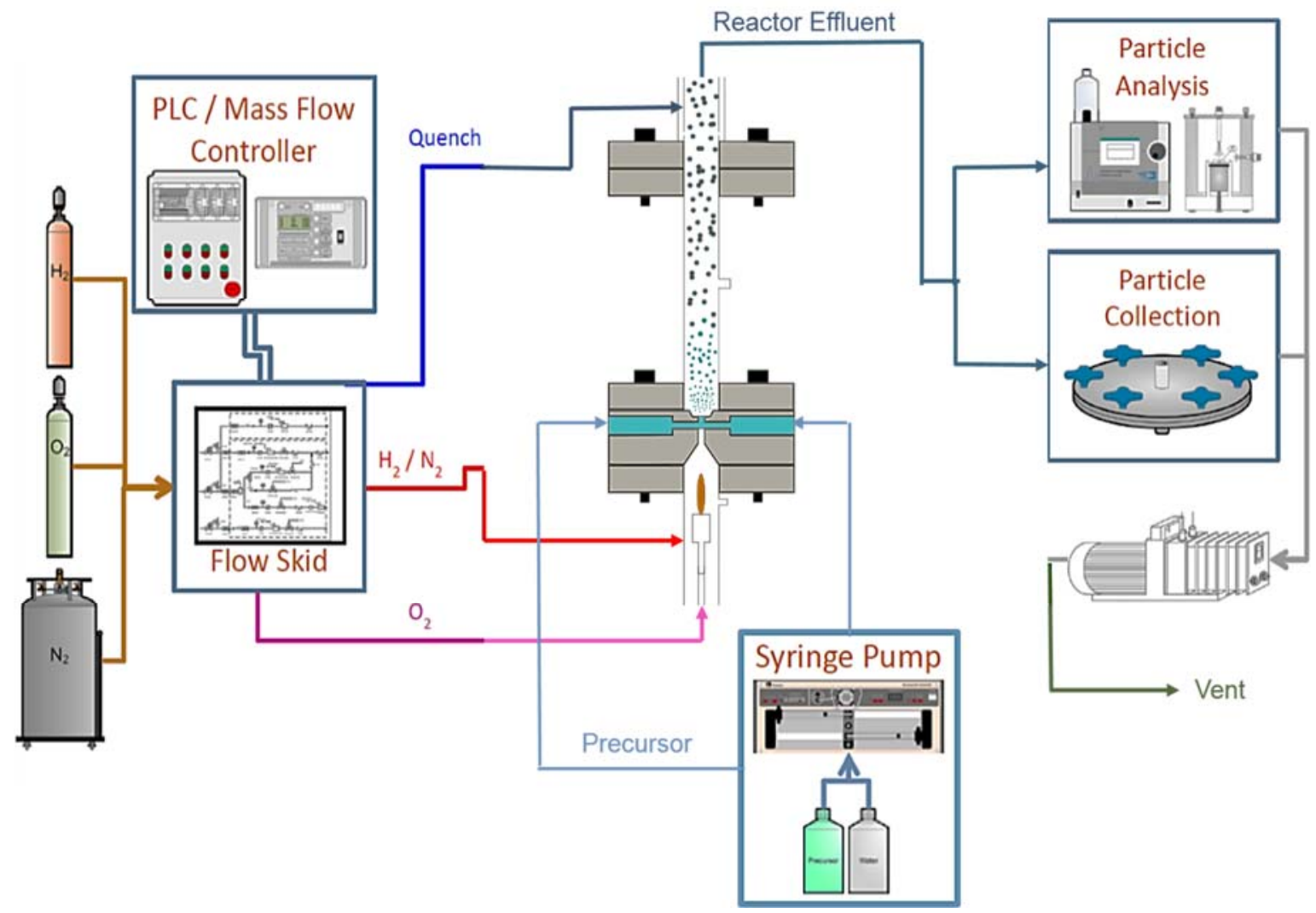

Figure S20. Schematic of the High Temperature Reducing Jet (HTRJ) process. Adapted with permission from Konda et al. ${ }^{\mathrm{S} 1}$ Copyright 2018 , American Institute of Chemical Engineers. 


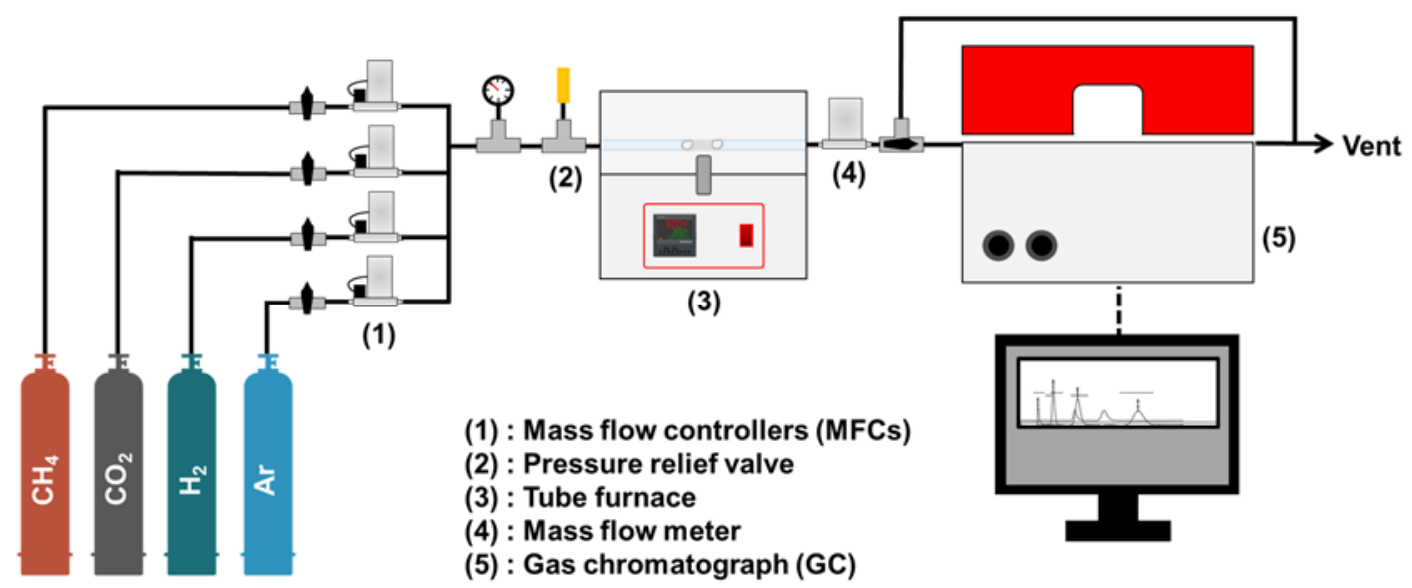

Figure S21. Schematic of the catalyst testing process.

\section{References:}

(S1) Konda, S.; Mohammadi, M. M.; Buchner, R. D.; Lin, H.; Swihart, M. T. Flame-based Synthesis and in situ Functionalization of Palladium Alloy Nanoparticles. AIChE J. 2018, 64 (11), 3826-3834. 